\title{
A Landscape Changes of Georgia: Estimation of an Integrated Parameter
}

\author{
Dali A. Nikolaishvili, Lia G. Matchavariani and Roman G. Maisuradze
}

\begin{abstract}
An integrated parameter has been elaborated to estimate landscape changes based on the concept of spatial-temporal analysis and synthesis of natural territorial complexes (NTCs) enabling to study components of nature applying the unified methodology. To achieve the purpose a great number of statistical data (censuses of Georgia, area of agriculture lands, number of industrial enterprises, and length of transport network), long-term field-work observations in different landscapes, cartographic and fund materials were made use of. The entire data were processed by means of GIS-technologies. The cartographic base of the research is the landscape map of Georgia. The object of the study is the entire territory of Georgia. On the basis of Geographical inventory of landscapes and Landscapes GIS database an integrated parameter of landscape changes was elaborated on the example of Georgia, also the degree of landscape changes and its spatial distribution were revealed according to different landscape units.
\end{abstract}

Index Terms - an integrated parameter, Georgia, landscape changes, landscape inventory, natural territorial complexes

\section{INTRODUCTION}

Contemporary epoch is regarded as the epoch of systemic crisis which is diverse and all-embracing. Therefore, scientific researches should be focused on complexity and on complex vision of problem solving. Recent interest rise to landscape studies can be explained by the fact that any landscape does not represent just a simple combination of components of nature. It is a dynamic system with a complex interconnection of natural components, undergoing constant changes due to the influence of natural or anthropogenic factors. The analysis of this complex interconnection is one of the basic goals of landscape study which has both theoretical and practical significance.

To establish landscape changes one of the main things needed is to elaborate an integrated parameter based on the multifactor analysis. However to resolve this issue is rather difficult as it should be based on comparison of different dimensional parameters and development of a single, integrated parameter on this basis. This approach makes it possible to estimate natural-resource potential of landscapes, modern condition and current trends not only according to their separate components but according to their integrity. This particular approach will enable us to create scientifically grounded basis for sustainable use of natural resources, territorial planning and environmental protection. Another important advantage in this approach is systematization of the data scattered in geographic branch literature and different scientific-research institutions and as a result, formation of a unified database.
A. Isachenko points out that our knowledge of natural complexes is insufficient and uneven, and that time has come to unite them in one system and create a single databank [1]. Geographical data need ordering and classification, which is possible by means of the landscape inventory and GIS. Special significance in applied landscape science is attaches to the solution of this problem. Landscape inventory is necessary, first of all for the estimation of natural components as well as the whole complex, for organizing their rational and sustainable use, their protection and planning. Landscape inventory will promote the accumulation and systematization of different branch-geographical data, their coordination to landscapes, for carrying out monitoring and forecasting while making different constructive decisions.

It is important to find a tool enabling us to establish the degree of landscape changes, their spatial-temporal distribution, expected trends, especially that of the endangered areas and as the main task, their prevention and mitigation terms. From this point of view the landscape approach is the most representative as any landscape reflects all the changes related to anthropogenic impact, as a "mirror.

The main goal of the present study is to develop an integrated parameter of landscape changes and reveal the highly endangered landscapes by the changes expected.

\section{OBJECTS}

The object of the study is the entire territory of Georgia, which is located at the junction of subtropical and moderate climatic zones (the border between them passes along the Main Caucasus range), determines the regional climatic differences. Also, topography and high altitude peculiarities determine the diversity of types and vertical zonality of Georgia's landscapes. The diversity of landscapes is closely connected with geological factors (distribution of limestone and volcanic rocks), and with Quaternary period with cooling of the climate, although many of species of Tertiary flora survived in Colchic refugia (mainly in foothills of Western Georgia). Georgia is characterized by a high level of flora and fauna endemism.

Georgia is distinguished by its landscape diversity and even exceeds many other countries in this respect. On average, more than 3 types of landscapes fall on every 10 thousand $\mathrm{km}^{2}$ area. There are landscapes varying from humid subtropical in West Georgia, semiarid and arid in East Georgia, to meadows, subnival and glacial-nival in high mountains. There are 14 types, 23 subtypes, 71 genera of landscapes and more than 300 types of NTCs in Georgia [2], 
[3].

One major peculiarity of Georgia is the existence of a comparatively large amount of intact and even virgin landscapes. Virgin forests that comprise almost $10 \%$ of total territory of Georgia are particularly significant [4]. Forest as such occupies $40 \%$ of the total territory. Against the global background, Georgia is a relatively unaffected 'island' with few environmental "hot spots [5].

However, anthropogenic factors are one of the most important driving forces of landscape changes. As a result of anthropogenic impact new agricultural lands, urban areas, degraded ecosystems, and polluted territories are being formed. Natural disasters have become rather intensive recently, resulting in serious economic loss. Therefore, determining of landscape changes of Georgia is one of the most necessary preconditions for the solution of a sustainable use of natural resources, territorial planning and environment protection.

\section{Methods AND Materials}

The work is based on the concept of spatial-temporal analysis and synthesis of NTCs, which was developed in 1980s at Tbilisi State University (Laboratory for Studying Environmental Conditions by Space Methods, Martkopi Physical-geographical Station) under the guidance of Prof. N Beruchashvili. The main value of the concept is that it enables to study natural components applying one methodology; we can investigate conditions of NTCs, peculiarities of their structure and functioning, as well as modern condition and the degree of anthropogenic transformation of landscapes. A lot of studies have been carried out in this sphere. However, many aspects still remain uninvestigated.

In the presented work, landscapes of Georgia are examined at the level of genera and types of vertical structure of NTCs. The study is based on different scales $(1: 1,000,000$ and 1:500,000) landscape maps.

To reveal the landscape change integrated parameter we have made use of 7 basic parameters which are best to show the changes degree. All these parameters were defined according to the genera of landscapes in Georgia (71 units).

Forest area and phytomass reserves are defined on the basis of the scientific literature $[6 ; 7 ; 8]$ and field data (about 600 experimental plots), obtained during the research carried out in 1980-2005. These materials cover the entire spectrum of Georgia's landscapes from plains to high mountain alpine and subnival landscapes and represent a description of complex geographical peculiarities of landscapes, including vertical structure of NTCs and landscape-geophysical features. The field studies involved absolute majority of Georgia's landscapes ( 9 out of 14 types of landscapes spread in Georgia, 17 out of 22 subtypes and 41 out of 71 genera). The degree of forest area changes was measured after comparing and correlating the map of restored vegetation [9] and landscape [3] maps, which reflect two historically different periods. The map of restored vegetation shows the spread of vegetation cover in the past, before the anthropogenic factor became stronger. The map of landscapes shows the distribution of the types of vertical structure of NTCs at the end of the 1990s. The correlation enabled to determine not only the summarized data of the degree of changes for whole Georgia and its separate regions [10], as well as for each individual landscape.

On the basis of topographic and landscape maps (scale 1: $500,000)$ the area of arable lands and pastures, degree of landscapes fragmentation and transport network density as well as the share of agricultural land in the total area of landscape genera were defined. Statistic data (population census of 1989 and 2002, number and type of industrial enterprises) were used in this study on the basis of which population density and industrial entities number (more than 2500) were stated according to the landscapes related. All the data was processed by GIS.

This was investigated in three stages). The first stage comprises data collection and their matching with landscapes. This means data collection about landscape units from several institutions. On the second stage the database of GIS should be created, the fulfillment of which is possible by means of using GIS-procedures (overlay). On the basis of the obtained information certain parameters will be determined according to different landscapes. From the viewpoint of landscape approach, the third stage is the most significant. In particular, landscape changes are defined by integrated parameter. Special attention should be paid to the ongoing tendencies in the landscapes and to determining the landscapes suffering from a huge influence of the population and different economical branches.

There are the certain problems connected with methodological complexity of comparing the data, particularly because of the fact that the data accumulated in branch-geographical literature and also in various institutions has been gathered using different techniques. Therefore, it is often difficult to interconnect the data of several natural components, and for landscape research these interconnections are of great importance. In the given case, the way out of this situation may be carrying out the program procedures, which will provide the overlay of different thematic map layers, the creation of uniform database and the resolution of problems connected with the "inconsistency" borders.

\section{RESULTS}

To reveal the landscape change integrated parameter were estimated several parameters such as the change of forest area from early stage of society development up to present, the share of agricultural land in the total area of landscape, the degree of fragmentation of landscapes, the coefficient of demographic influence, the density of industrial enterprises, and the density of transport network. On the basis of applying the method of data balancing each of the parameters was defined within one and the same interval (1-10) that enabled us to perform their comparison [11]. Besides, it has enabled us to reveal the share of each parameter in landscape changes (Fig. 1). 


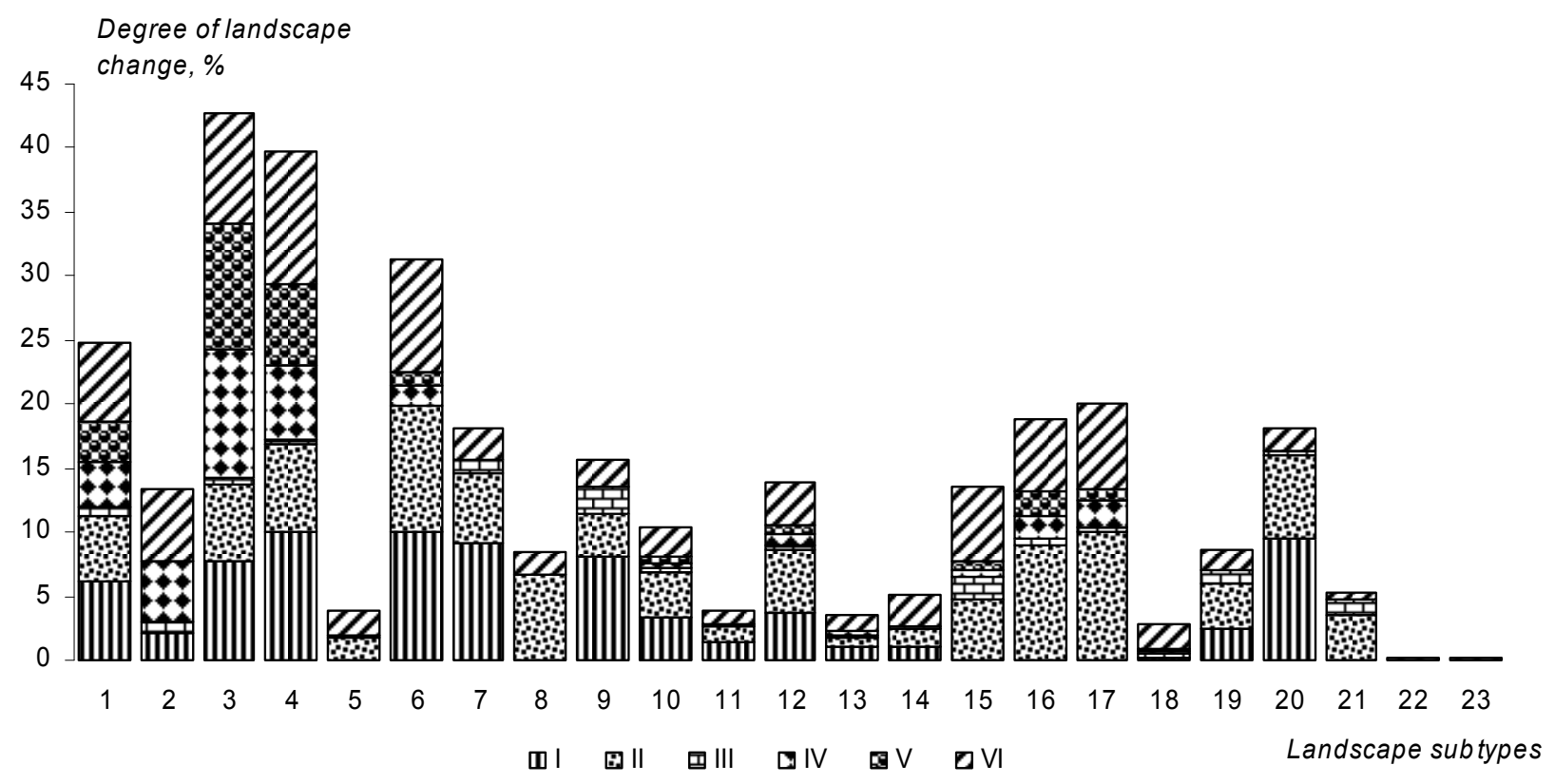

Fig.1: Degree of Georgia's landscapes changes

\begin{abstract}
I - change of forest area from early stage of society development up to present; II - the share of agricultural land in the total area of landscape; III - the degree of fragmentation of landscapes; IV - the coefficient of demographic influence; V - the density of industrial enterprises; VI - the density of transport network.
\end{abstract}

Parameters analysis according to the landscapes genera has shown that the changes tend to be different. The picture is very diversified not only according to mountain and plain but according to one type and subtype of landscapes. For example, forest area reduction along with other factors played an important role in the changes of the Colchic forest landscape (landscape subtype) of Western Georgia. However, the situation is very diverse by the landscape genera. Within one genus of landscapes the forest area has reduced at $30 \%$, while within another - just at $4 \%$. We can list many examples of the kind.

Georgia's environment underwent a significant change in XX century, especially in the plains where two-thirds of the territory was transformed. Woods were especially intensively cut between the 1930s and 1950s. Later, a certain part Georgia's forest cover was assigned to the first category, therefore commercial logging was strictly limited. As a result, large forest areas have remained comparative untouched. Due to the energy crisis and hard socio-economic conditions, in the 1990s the population impact upon forest areas increased. Some forest cover, which was considered untouched for centuries, was destroyed. As a result of forest destruction in Georgia, geodynamic processes have become frequent phenomena. This itself causes an overall decline in forest productivity and regeneration rate of forest in some landscapes. But in some parts of Georgia, a "strange" situation - the increase in the area of forests - is still observed. In particular, the comparison of 1989 and 2000 RS data (LandSat) of central part of Great Caucasus range, has shown insignificant reduction or even increase in the area of forest cover in some parts Georgia. For example, pine forest growth areas observed in Racha, where in the last few years its area has grown by $5-10 \%$ [5]. The reason for this is the depopulations of some mountainous regions of Georgia.

The plain landscapes have experienced the most significant changes, which occupy 17.56 thousand $\mathrm{km}^{2}(1 / 4$ of whole territory of Georgia). Since the early days of human development, the forest area has decreased by $70 \%$ and supply of phytomass by $37 \%$ [8]. The largest agricultural areas are spread in the plain and foothills landscapes. There, more than $60 \%$ lands are cultivated. Large agriculture areas are also located in other landscapes of Georgia, such as high plateau steppe landscapes of South Georgia. The plains are marked with a high coefficient of demographic influence (density of population - 323 inhabitants on 1 thousand $\mathrm{km}^{2}$ ), the share of agricultural lands in the whole territory of landscapes $(62 \%)$ and transport network density (635 $\mathrm{km} / \mathrm{km}^{2}$ ). The degree of forest area change is higher in Eastern Georgia. Likewise, the plain landscapes of Eastern Georgia demonstrate considerably more changes according to other parameters. Many landscapes which in the past were covered with forest today are represented with meadow-steppes, light forests, wood derivatives and agricultural lands.

Amongst the mountain landscapes, low mountain landscapes (with prevalence of oak forests, and oak-hornbeam forests) have undergone the most considerable changes, which occupy 13.64 thousand $\mathrm{km}^{2}$ areas (about $20 \%$ of whole territory of Georgia). It can be explained by their proximity to human settlements and less complexity of topographic conditions. Here the forest area has been reduced by more than a third from the early stage of human development up to present. More significant changes took place in the upper mountain landscapes (with prevalence of beech, birch, partially with pine and oak) in comparison with the middle mountain landscapes (with the prevalence of 
beech and dark coniferous forests), which is also logical. Due to complex topographic conditions, the middle mountain forest landscapes are better preserved in their original state
$1 \%$ of the whole area of Georgia, and strongly changes $19 \%$. The greatest area, more than half of the territory (58\%) of Georgia, is occupied by poorly changed landscapes. Thus,

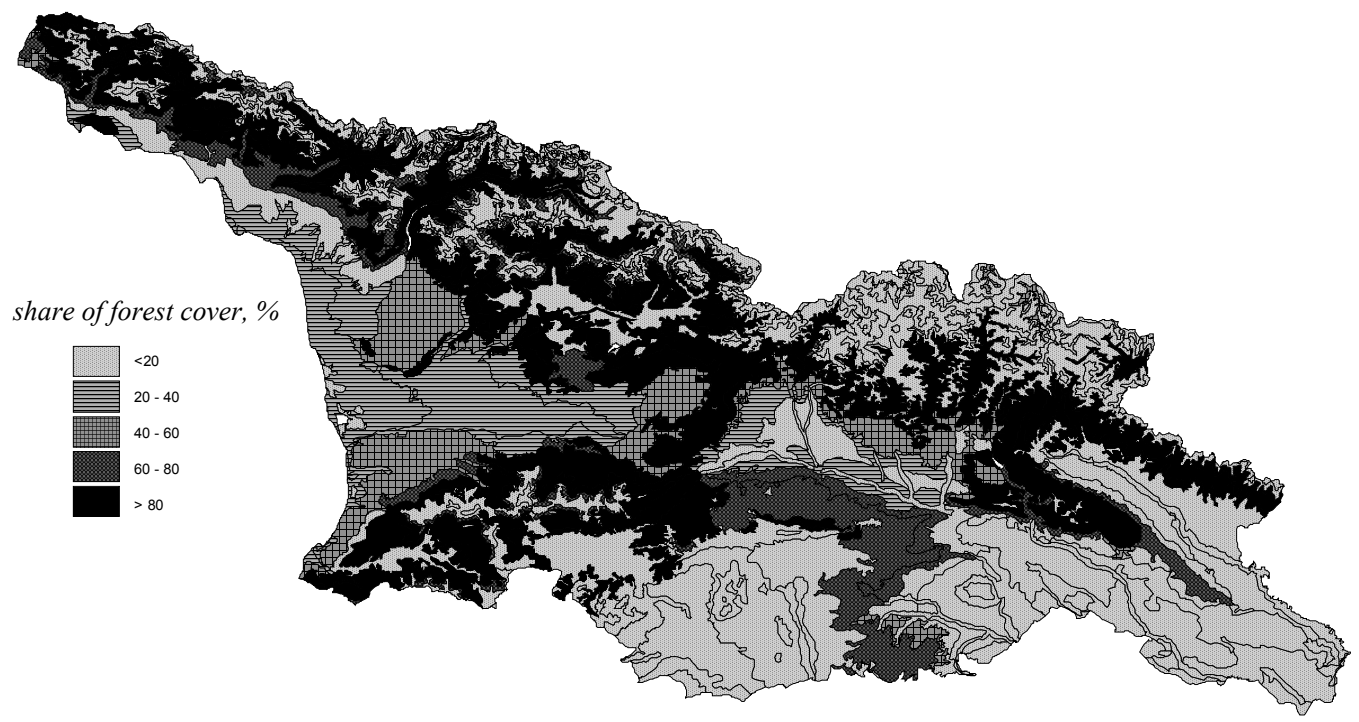

Fig.2: Forest cover of Georgia's landscapes

(reserve of phytomass is maximum for Georgia) than those located in the upper and high mountain subalpine and alpine landscapes (Fig. 2), since anthropogenic influence results in overgrazing in these areas. From the early stage of human development until present, the degree of decrease of forest area throughout the middle mountain fluctuates within $10 \%$, while for the upper mountain forest landscapes it reaches $25 \%$ due to their high sensitivity.

Reduction of phytomass amount provides a clear picture of landscape changes' degree. It has obviously reduced in the landscapes mostly where forests occupied significant area in the past. Besides, diverse modifications of landscapes transformation are the highest here. Consequently, for these landscapes it is typical to have greater range of phytomass volume changes. The widest range of phytomass amount changes is characteristic for the lower mountain forest landscapes where NTCs are distinguished with less than 50 $\mathrm{t} / \mathrm{ha}$ and with more than $600 \mathrm{t} / \mathrm{ha}$ amount of phytomass (Table. 1). This parameter is high in the upper mountain forest landscapes as well. It can be explained by the fact that on the one hand, the landscapes referred are adjoining the forest landscapes (middle-mountain forest) and on the other hand, (high mountain subalpine) landscapes with lesser forest areas or without any.

The highest amount of phytomass is characteristic to middle-mountain forest dark-coniferous landscapes in Georgia and it makes up $500 \mathrm{t} / \mathrm{ha}$ and higher, at average. The second by the amount of phytomass is middle-mountain forest landscapes with the prevalence of beech forests (300-500 t/ha) and the third - lower mountain Colchic landscapes (250-300 t/ha) [6]-[8]. These are the landscapes (not counting the high subnival and nival landscapes) which have mostly maintained their primary natural condition and are distinguished with the lowest degree of changes especially, those of the middle-mountain forests.

On the basis of the integrated parameter were determined that practically completely changed landscapes occupy only the highly endangered landscapes by the changes expected occupy no more than $20 \%$ of the whole area of Georgia. These landscapes are spread mainly in the plain and foothills, which is also logical.

TABLE 1. MAXIMUM AMOUNT OF PhytOMASS ACCORDING TO ABSOLUTE HEIGHT

\begin{tabular}{|c|c|c|}
\hline Landscapes & 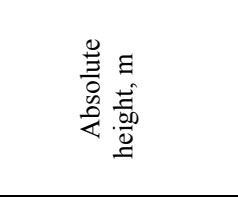 & 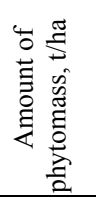 \\
\hline $\begin{array}{l}\text { Eastern Georgian hills with } \\
\text { steppes and dry shrub-lands }\end{array}$ & $900-1000$ & $50-80$ \\
\hline $\begin{array}{l}\text { Western Georgian low-mo- } \\
\text { untain forest (with pre- } \\
\text { valence of oak, hornbeam) }\end{array}$ & $600-750$ & $>400$ \\
\hline $\begin{array}{l}\text { Western Georgian middle-- } \\
\text { mountain forest (with preva- } \\
\text { lence of beech) }\end{array}$ & $1200-1400$ & $>450$ \\
\hline $\begin{array}{l}\text { Eastern Georgian middle-- } \\
\text { mountain forest (with preva- } \\
\text { lence of beech) }\end{array}$ & $1200-1400(1800)$ & $>300$ \\
\hline $\begin{array}{l}\text { Western Georgian middle-- } \\
\text { mountain forest (with preva- } \\
\text { lence of beech-coniferous) }\end{array}$ & $1400-1800$ & $>500$ \\
\hline $\begin{array}{l}\text { Eastern Georgian middle-- } \\
\text { mountain forest (with preva- } \\
\text { lence of coniferous) }\end{array}$ & $1600-2000$ & $>500$ \\
\hline Upper-mountain forest & $1700-1750$ & $>150$ \\
\hline
\end{tabular}

\section{CONCLUSIONS}

Thus, on the basis of the concept of spatial-temporal analysis and synthesis of NTCs and taking into consideration the basic factors defining anthropogenic transformation of territories:

1) A methodology for determination of an integrated parameter of landscape changes has been elaborated. This method is representative for the assessment of the modern condition of the landscapes. 
2) Landscape changes degree and share of different parameters in the changes are stated.

3) Using this calculation, some specific features of territorial distribution of changes have been revealed according to the different units of landscapes.

4) A degree of forestation of Georgia's landscapes has been completed. This map allows comparing different landscapes and using quantitative data for the assessment of their modern condition.

\section{ACKNOWLEDGEMENTS}

This work was supported by field data, collected by the employees of Research Laboratory for Environmental Studies of Tbilisi State University.

\section{REFERENCES}

[1] G.A. Isachenko, A.G. Isachenko. Optimization of environment. Moscow: Misl, 1980. 264 p. In Russian.

[2] N.L. Beruchashvili. Landscape Map of Caucasus. Tbilisi: TSU, 1979. Scale 1:1,000,000.

[3] N.L. Beruchashvili. Landscape Map of Georgia. Types of Vertical Structure of Natural-territorial Complexes. Tbilisi: TSU, Fund material. Scale 1: 500,000.

[4] L. Beruchashvili. Diversity of Georgia's Landscapes and Geographical Analysis of Landscapes Diversity of the World. Proc. of the First National Conference: Biological and Landscape Diversity of Georgia. Tbilisi, 2000, pp. 221-250.

[5] Caucasus Environmental Outlook (CEO 2002). UNEP/GRIDTbilisi, 2002, 100p.

[6] N.L. Beruchashvili. Caucasus: Landscapes, Models, Experiments. Tbilisi, UNEP-GRID, 1995. In Russian.

[7] A.G. Tediashvili. Research of phytomass as landscape-geophysical parameter of NTCs and it's conditions. Tbilisi: TSU, 1984.

[8] D. A. Nikolaishvili. Spatial-Temporal Analysis of Georgia's Landscapes. Tbilisi State University Publishing House, 2009. In Georgian.

[9] N.N. Ketskhoveli. Map of Restored Vegetation of Georgia. Tbilisi, 1959. Scale 1:500,000. In Georgian.

[10] D.A. Nikolaishvili. Area over the Territory of Georgia from the Early Stage of the Human Society till Modern Days. Siberian Journal of Ecology, Novosibirsk: Siberian Branch of the RAS, 2008, 15 (2): 225-228.

[11] N.V. Kobisheva, O.B. Ilina. Methods of Evaluation and zoning of Climatic Resources of Lenindgradskii Krai. In: Meteorology and Hydrology. Moscow, 2001, 9: 17-24. 